\title{
SYSTEM APPROACH FOR PROBLEM SOLVING APPLIED TO THE STORM WATER DRAINAGE
}

\author{
Mateusz, Stupiński \\ Janusz Jeżowiecki \\ Wroclaw University of Technology, Poland
}

\begin{abstract}
The solutions in the storm water evacuation systems have developed in the past and are developing into the future. It is desired to learn about their evolution from the point of view of the evolution of technical systems. Knowledge about the system evolution can be used to speed up the evolution and to propose the new solution advancing in the correct direction. In order to start the analysis of the technological system evolution, it is necessary to describe the problem identified with the system of storm water evacuation and then to define the parameters which allow the positioning of the system on the evolution line. In this paper we propose the formulation of the problem in the form of contradiction. We also propose the parameters which can be used as index of development in the storm water evacuation systems. Finally, we pose a question about the future development of the solutions in the storm water evacuation systems. The intention of this paper is to make an introduction into the research of the technical system evolution of the storm water evacuation system.
\end{abstract}

\section{KEYWORDS}

Storm water evacuation system; Evolution of technical system; Evolution index.

\section{INTRODUCTION}

\subsection{Problem solving approach}

Problem solving approaches are composed mainly of problem analysis and its modeling. The utilization of the problem solving approaches gets more efficient when it takes the systemic point of view of the analyzed problem situation and its environment. The systemic approach organizes and presents the situation in the form of a system which is being explored during the analysis. Taking the point of view of the system analysis the objective of the analysis is to describe the elements and the relations between these elements. In the result of the analysis of the system it is possible to identify the key problems in the system. The solution to the key problems should resolve also other difficulties preventing the system to realize the required objective. There are many known tools for the problem solving. The popular tools applied in the engineering practice are usually profiled for the particular application e.g. management of the production process, solution in the engineering design. There are also tools which are part of larger approaches e.g. Causal Loop Diagram (CLD) is a model used in the System Dynamics. In general, the systematic problem solving approach should realize the following functions:

- Management of the problem solving process

- Organization of the precise definition of a problem 
- Definition of a border of the system

- Description of the aim, the ideal solution

- Support by the problem analysis and problem solving tools e.g. concepts, models, rules, techniques

- Transition from the theoretical solution to the practical application of the solution

In this paper we would like to propose the utilization of the few general concepts form the systematic problem solving approach. These concepts are generally recognized in several problem solving approaches but in our work we were inspired by the General Theory of Strong Thinking which is an upgrade development to the Theory of Inventive Problem Solving (TRIZ acronym in Russian). Together it is called OTSM-TRIZ.

\subsection{The water evacuation systems}

Until now, the storm water evacuation systems have been evolving longer in time than the sewage systems. This assumption does not claim that the storm water evacuation system has evolved more than sewage systems; however it has had more time to do so. The claim about the succession of these systems is based on the initial definition of the water evacuation system, which we propose to state here as the system to secure the building and other structures from the water penetration e.g. evacuation of the water from the roof and protection from the direct contact with walls. The development of the storm water evacuation was taking place along the development of the sewage systems and therefore these systems have much in common. Nowadays the main concern of the storm water evacuation system is its deployment in the city system and cooperation with the other elements of the infrastructure of the urban area. Additionally, the concepts of Low Impact Development (LID) and local natural retention of storm water, have introduced the interesting constraints for the future development of the system for storm water evacuation. [13]

\section{DESCRIPTION OF THE SYSTEM}

According to the definition of the system by Ludwig von Bertalanffy the description of the elements of the system does not provide the complete information about the system. It is necessary to know the relations between elements of the system.[3] The most convenient way to describe the system at the beginning of the analysis is to follow the process taking place in the system. In this way we learn about the known elements and relations.

The principal task of the considered system is the evacuation of the water in order to maintain the usability of the other infrastructure systems e.g. pavements, roads, parking lots and to prevent the short or long term destruction caused by the water penetration e.g. water removal from rooftops, drainage around buildings. Traditionally, the water evacuation system used to be designed to remove the collected water and transport it to the receiver body of water or to the sewage treatment plant.

\subsection{Definition of the border of the system}

The storm water evacuation system is a system from the domain of environmental engineering. The characteristic feature of the systems in environmental engineering is their long border with the environment, but what is considered as a system and what is its environment in our case? In order to state it clear it is necessary to define the border of the system similarly as we do when describing the border of the system with thermal process in 
order to measure the heat exchange with the environment. Description of the border is not easy or obvious and it may be modified later on during the problem solving process.

We propose to define two kinds of borders which will be useful to describe the problem in the further steps. One border it is a strict engineering system of the storm water evacuation which starts at the intake point e.g. catch basin grate, roof gutter, then the system is limited by the system of drains. On the other end there is a receiving body of water. Second description of a border can be defined as a larger input when we consider the entire surface where the rain falls, whether connected to the water evacuation system or not.

The input to the system is the rainfall water with the airborne pollutants and solid pollutants collected from the surface e.g. from the pavement, road, roof. The output of the system is the same water including solid or liquid pollutants with accidental water infiltration to the drains or illegal discharge of waste water.

Exchange between the system and environment takes place mainly by the input and output of the rain waters. However, in case of the designed retention of the water, there are also other ways of influence by infiltration, evaporation and transpiration. An interesting list of effects on the environment is presented in [4].

\section{DESCRIPTION OF THE PROBLEM}

The problems commonly associated with the storm water evacuation system are referring to the water transportation subsystem (subsystem is a system included in the main system) and the quality of the transported water. The problem with the water transportation subsystem is caused by the high irregularity of the stream, from zero when there is no rain up to maximum or above maximum during the maximal rainfalls. The other problem is the pollution carried with the stream. It can no longer be selectively separate like in the semi-separate sewage systems, because according to the research the pollution of the storm water remains above limit during entire time of the rainfall. [10] The pollution of the storm water evokes the need for treatment before the discharge to the environment. Storm water treatment performed in the sewage treatment plant together with sewage, causes the change in parameters i.e. temperature, pollution characteristic and in volume.

The new need which appeared in connection with the storm water evacuation is the need for water retention, which is also intended to partially solve the above described problems.

Basing on the two above mentioned problems, which can be called variable flow and need for treatment, it is possible to formulate the problem which we are going to study more in the future research. The problem will be formulated here using the model of contradiction, widely applied in the OTSM-TRIZ theory.

The contradiction includes the positive and negative values of the two parameters in conflict with each other. The required result is to attain the positive value of both parameters $\mathrm{P} 1(+)$ and $\mathrm{P} 2(+)$ at the same time. (See Figure 1) The formulation of the problem and solution process is conducted respecting the three postulates, which are the base of the theory. TRIZ addresses only systems where the evolution of the system requires the solution of a contradiction. This excludes the systems where evolution is performed by the optimization. First, the problem has to be formulated as a contradiction. Second, there are the laws of the evolution of the technical systems, which are used for the problem solving. Third, the problem and the solution to the problem exist for the particular situation conditions. 
There exist several kinds of contradictions. In TRIZ language, there are administrative, technical and physical contradictions. OTSM-TRIZ distinguishes administrative, parameter and system contradictions. To learn more about contradictions see [6].

According to the rules of the TRIZ, all problems have the place in the evolution of the technical system where they are located. The solution of the problem is a powerful solution only if it resolves contradiction towards the increase in the ideality ratio. The solution should e.g. increase the functionality and decrease expenses. [1, 2, 5, 7].

Using the presented model of contradiction, the problem of the overflows and the need for retention can be formulated in the form of technical contradiction as follows. There is a need to remove the storm water in order to maintain in operation of the infrastructure and at the same time there is a need to not remove the storm water in order to not cause the water deficit. (see 0 a.) The need to provide the water treatment of the storm water can be formulated in the form of contradiction as follows. We would like to have clean storm water in order to not use the purification process and at the same time we would like to have polluted water in order to remove the pollutants from the urban area. (see $0 b$.)

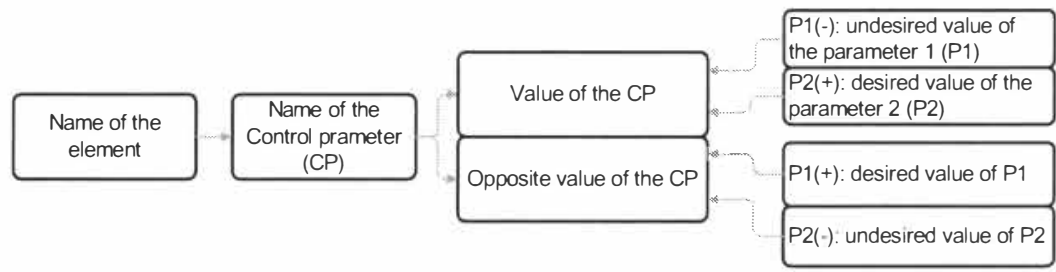

Figure 1. Contradiction: Elements of the model (CP-Control Parameter, PI, P2 parameters).

\section{DEVELOPMENT OF THE SYSTEM - EVOLUTION}

From the point of view of the evolution of the technical system, the system of the storm water evacuation has evolved using the resources of the nearest super-system (system which is above in hierarchy and includes the system considered by us) which is the sewage system, it is in fact an element of the system for removal of the liquid wastes. The utilization of the resources of the nearest super-system resulted in solutions of semi-separated sewage system and combined sewage system. In order to resolve the problem of retention, the storm water evacuation systems started to consider and apply the solutions of the local retention e.g. natural retention, rain gardens and rooftop gardens. This is also an example of evolution where the system is using the resources from the nearest super system. $[9,11]$

The evolution of the technical systems can be presented as a curve. One of the ways to present it is the form of the S-curve introduced by Pierre Verhulst. [12] The S-curve presents the development of the system as the $S$ shaped curve. It is positioned by two axis: time and the main indices of the system. With time the system develops along the one line representing one solution, then there is a decline in the development when the main solution concept used all 
the resources. Before this moment of decline the new solution appears and soon it will take over the evolution of the system to the next S-curve. (More about S-curves in [8]).

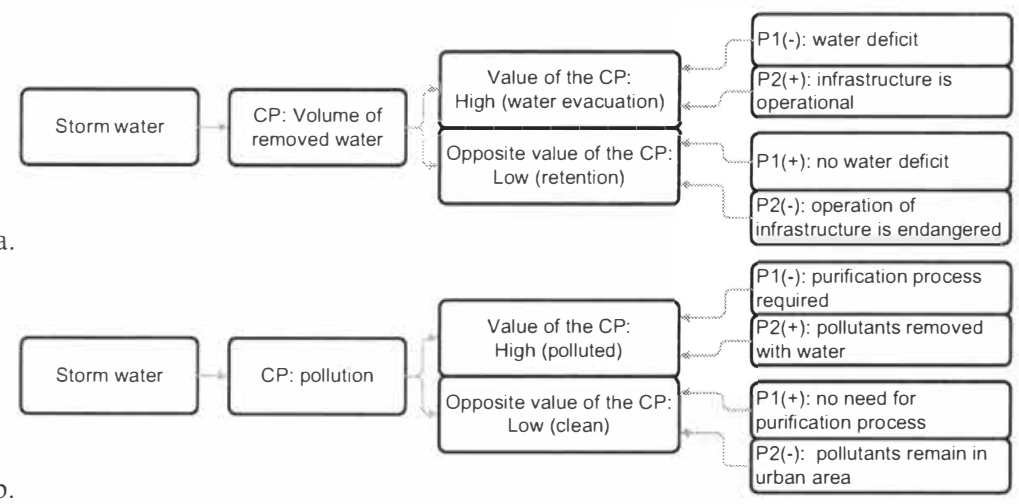

Contradiction: a) remove and retain, b) storm water treatment.

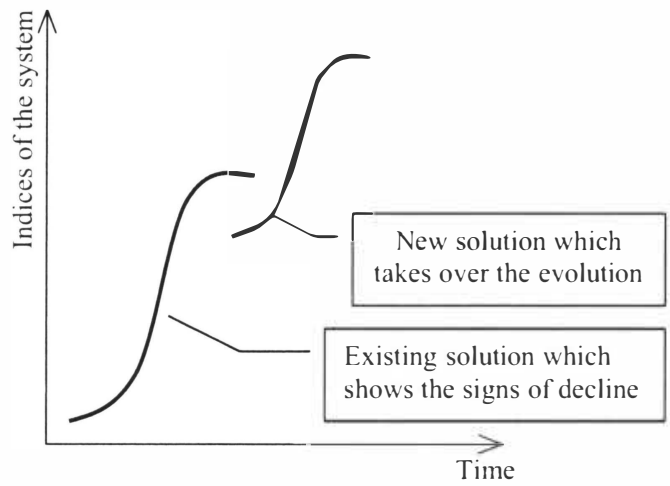

Figure 2. S-curve of the evolution with two solutions.

In the case of the evolution of the storm water evacuation system we can observe the development of several solutions like combined, separated and semi-separated systems with all service utilities applied in the drains to support and upgrade these solutions. Right now we can observe the new solution which will evolve, this is the storm water evacuation system with the elements of retention. The conventional retention solutions will develop along this $\mathrm{S}$ curve until the utilization of all available resources.

The objective of the analysis of the S-curve is the identification of the current position on the S-curve and then identification of the next S-curve, when it should appear. Some analysis goes even further with the attempt to identify the second S-curve from present. 


\subsection{Utilization of the resources for retention}

The example of resource for the water transportation in the water evacuation systems are listed in the Table $I$.

The utilization of the above mentioned resources will grow until their use up in the currently employed form. Then the new solution should appear which will use different resources for further development.

\subsection{The proposition of the evaluation parameters for the development of the storm water evacuation system}

In order to position the evolution of the storm water evacuation system on the $\mathrm{S}$ shaped evolution line, it is necessary to choose the parameter for evaluation of its development e.g. evolution of the internal combustion engine can be measured by the parameter constructed from engine's efficiency, size and engine cubic capacity. Here are the few propositions which will be used in the further research in order to position the evolution of the analyzed system on the evolution line:

- Self regulation and maintenance of the system

- Storm water treatment

- Water retention - only for the recent development

- Covered area

Table 1. Example of the resources in the system of storm water evacuation.

\begin{tabular}{ccc}
\hline Type of resources & Name of the resource & Function realized by the resource \\
\hline Field & Infiltration & $\begin{array}{c}\text { Transportation of the water to the } \\
\text { lower elevated location. }\end{array}$ \\
\cline { 2 - 4 } & Evaporation & $\begin{array}{c}\text { Transport of the water to the } \\
\text { groundwater }\end{array}$ \\
\hline Transpiration & $\begin{array}{c}\text { Remove of the water from the site, } \\
\text { increase of humidity, decrease of } \\
\text { the temperature. }\end{array}$ \\
\hline Construction & $\begin{array}{c}\text { Remove of the water from the site, } \\
\text { increase of humidity, decrease of } \\
\text { the temperature }- \text { intensity } \\
\text { regulated by plants. }\end{array}$ \\
\cline { 2 - 4 } & Rooftop garden & $\begin{array}{c}\text { Limitation of the water runoff } \\
\text { from the roof. }\end{array}$ \\
Rain garden & Bioretention \\
Wet ponds & Retention \\
\hline
\end{tabular}

\section{SOLUTION OF THE PROBLEM IN TIME, SPACE OR BY ORGANIZATION}

In this section we would like to propose the one of the standard approaches to the problem solving. The approach starts with the concept that each solution can be attained at one of three different levels: in time, in space and in organization. The application of this approach to the storm water evacuation system is promising because the main frame of the approach evokes ideas corresponding to the problems defined in the system and main available resources. The 
solution to the problem of crossing the street well demonstrates the application of the concept of the solution in time, space and organization. A person, has to cross the busy street occupied by cars. The solution in time is to set up a light signalization which stops the traffic and let the people cross the street. This is a separation in time. The solution in space is to make a passage under or above the street. This is a separation in space. The solution in organization is to paint the stripes, the zebra crossing. This solution sets the rule which introduces the regulation to the stream of cars and people crossing the street. Which existing or future solution in storm water evacuation system can be allocated to the each of these groups? (see Table 2)

Table 2. Example solutions in time, space and by organization.

\begin{tabular}{cc}
$\begin{array}{c}\text { Group of the solution } \\
\text { In time }\end{array}$ & $\begin{array}{c}\text { Description of the solution } \\
\text { Retention (store and release later) } \\
\text { Rain harvesting }\end{array}$ \\
\hline In space & $\begin{array}{c}\text { Local retention - maintain the natural distribution of the rainfall } \\
\text { Rooftop or other elevated storage in order to use the potential } \\
\text { energy for the water delivery e.g. to flush toilets in the building }\end{array}$ \\
\hline By organization & $\begin{array}{r}\text { Start retention with delay in order to prevent the overflows in the } \\
\text { network and the flooding. }\end{array}$ \\
\hline
\end{tabular}

\section{WHERE THE EVOLUTION WILL GO AND WHICH SOLUTIONS WILL BE PREFERABLE?}

This paper gathers facts about the storm water evacuation system and uses them in order to present the introduction to the analysis of the technical system evolution. The paper states also the question about the indices describing the evolution of the system for storm water evacuation.

The fundamental features and problems of the storm water evacuation system presented and analyzed in this paper are not sufficient to continue the analysis of the evolution but they give the notion of the concept which will be developed in the further research. The three sorts of solutions, in time, space and organization, have been introduced in order to stimulate the reflection about the next solution and current development. The question which can be posed is - which of the three regions is the most preferable to be a location of the future solution in the evolution of the technical system of the storm water evacuation?

The resources of time are limited because the volume of storage which can retain the water is also limited. The solution in space seems to be the most likely location of the next step solution. Current solutions demonstrate the potential for storm water management especially in the newly arranged areas. The solution by organization suggests the hypothetical solution of the network which will adjust to the location of the rain and decide to remove or retain the storm water.

\section{REFERENCES}

[1] Altshuller, G., 1999. The Innovation Algorithm: TRIZ, systematic innovation, and technical creativity. Worchester, Massachusetts: Technical Innovation Center

[2] Altszuller, H., 1975. Algorytm wynalazku. Warszawa: Wiedza Powszechna.(in Polish)

[3] Bertalanffy, L.V., 1969. General System Theory. New York: George Braziller 
[4] Jones, J.E., et al., 2005. Urban storm-water regulations - Are impervious area limits a good idea? Journal of Environmental Engineering-Asce, 131(2): p. 176-179.

[5] Kaplan, S., 1996. An introduction to TRIZ: Ideation International Inc.

[6] Khomenko, N., et al., 2007. A Framework for OTSM-TRIZ Based Computer Support to be used in Complex Problem Management, in International Journal of Computer Applications in Technology.

[7] Khomenko, N. and R. De Guio, 2005. Utilisation de la theorie TRIZ dans les metiers du BTP, in Les cahiers de l'INSA de Strasbourg, R.e. de Guio and S. Dubois, Editors: Strasbourg. p. 10-33.(in French)

[8] Kucharavy, D. and R. De Guio, 2007. Application of S-shaped curves, in ETRIA Conference TRIZ Future 2007: Frankfurt am Main, Germany.

[9] Lubick, N., 2006. Using nature's design to stem urban storm-water problems. Environmental Science \& Technology, 40(19): p. 5832-5833.

[10] Sozański, M.M., H. Bylka, and Z. Dymaczewski, 2002. Wodociagi i kanalizacja w Polsce : tradycja i współczesność. Poznań, Bydgoszcz: Polska Fundacja Ochrony Zasobów Wodnych.(in Polish)

[11] Thrall, L., 2006. Rain gardens stem urban storm-water flows. Environmental Science \& Technology, 40(4): p. 1093-1094.

[12] Weisstein, E.W. "Logistic Equation." MathWorld--A Wolfram Web Resource. http://mathworld.wolfram.com/LogisticEquation.html

[13] Williams, E.S. and W.R. Wise, 2006. Hydrologic impacts of alternative approaches to storm water management and land development. Journal of the American Water Resources Association, 42(2): p. 443-455. 